\title{
Attenuation Influence of Single Pile Reaming Effect on the Structural Parameters of Loess Foundation
}

\author{
WANG Zhijun ${ }^{1, a}$, LUO Jianwen",b, LI Rongjian ${ }^{3, c}$, Tan Yongguang ${ }^{4, d}$, Luo \\ $\operatorname{Han}^{5, e}$ \\ ${ }^{1}$ Company limited of Changqing Science and Technology, WeiYang Road, Xi'an, 710021, China \\ 2 Company limited of Changqing Science and Technology, WeiYang Road, Xi'an, 710021, China \\ ${ }^{3}$ Institute of Geotechnical Engineering, Xi'an University of Technology, Xi'an 710048,China \\ 4 Institute of Geotechnical Engineering, Xi'an University of Technology, Xi'an 710048,China \\ ${ }^{5}$ Institute of Geotechnical Engineering, Xi'an University of Technology, Xi'an 710048,China \\ a2285165829@qq.com, b1879878040@qq.com, clirongjian@xaut.edu.cn, d1430364879@qq.com, \\ 5510128531@qq.com
}

Keywords: single pile, reaming effect, structural loess, structural parameters, attenuation Abstract. From the aspect of a pile foundation in a structural loess area, this study analyzes the relationship between the generalized shearing strain and the generalized shearing stress of the soil mass around the pile under single pile reaming on the basis of the theory of cavity expansion. Through a triaxial test, this study generates the generalized shearing stress and strain relations under different stress levels. Loess structural parameters are introduced into the analysis of single pile reaming, and the attenuation changing rule of the loess structural parameters resulting from the reaming effect is studied. Under the influence of single pile reaming and within approximately two times of the pile radius from the pile axle, the structural parameter attenuation of the loess is severe. The influence range of single pile reaming is approximately two times of the pile radius, and the range exceeding four times of the pile radius is basically not affected.

\section{Introduction}

In the loess region, pile foundation engineering is widely used in building, highway, and railway engineering applications. The structural properties of loess directly reflect their special mechanical properties and influence the interaction between pile and soil. As a result, the rule that the pile foundation reaming effect causes the attenuation of structural loess in the loess foundation is an important subject of research.

In the study of loess structure, many scholars have conducted in-depth research on loess structure, including strain structural parameters [1], and stress ratio structural parameters [2]. On the basis of stress ratio structural parameters, Li et al proposed initial and load structural parameters, further enriching and perfecting the study of comprehensive structure potential theory [3]. These studies have gradually developed from theory exploration to the related geotechnical engineering evaluation of loess areas, thereby effectively broadening the study of structural loess. However, no study has explored the effect and assessment problems of the reaming effect generated in the process of pile driving in loess areas.

In the study of piling and reaming in the pile foundation, the theory of cavity expansion, as a theoretical analysis method, plays a significant role [4]. Ladanyi studied the theoretical analysis of reaming in clay foundation [5]. Collins et al studied the analytical solution of reaming under the critical state of soil foundations [6]. These studies about pile reaming have greatly promoted the relevant theoretical research and evaluation of pile foundation reaming in the soft soil area. However, the influence of pile reaming on structural loess or the structural parameter change rule of structural loess has not been thoroughly explored. Therefore, the study on the influence law of pile reaming in loess foundation on loess structural parameters carries theoretical significance.

On the basis of the theory of cavity expansion, the present study acquires the generalized shearing stress and strain relations under the condition of different stress levels by performing a triaxial test. In 
addition, this work analyzes the changing rule of the generalized shearing stress and strain of the soil mass around the pile under single pile reaming. Loess structural parameters are then introduced into the theoretical analysis of single pile reaming to deduce the theoretical formula of the attenuation of foundation loess structural parameters under the single pile reaming effect. Finally, this study performs a calculation analysis of single pile reaming under $\mathrm{Q}_{3}$ loess layer according to a pile test project in a loess plateau to evaluate the change rule and influence scope of loess structural parameters under the effect of single pile reaming.

\section{Generalized shearing stress and strain in single pile reaming in soil}

The pile foundation driving process can be considered as a process in which the cylinder cavity expands with the same radius as the pile radius in infinite soil (Fig. 1).

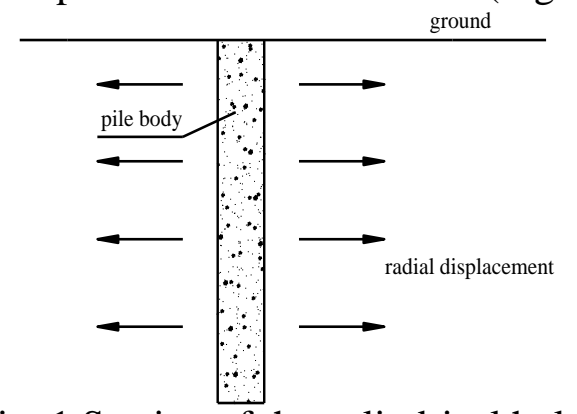

Fig. 1 Section of the cylindrical hole after cavity expansion

As an infinitely long hole expansion can be simplified into an axisymmetric problem, the principal stresses are vertical, tangential, and radial stresses. We take a unit for analysis from the location with distance $r$ from the pile axle, as shown in Fig. 2. The symbols are as follows: $\sigma_{z}$ is the vertical stress of soil elements, $\sigma_{r}$ is the radial stress of soil elements, $\sigma_{\theta}$ is the tangential stress of soil elements, $\mathrm{d} z$ is the thickness of soil elements, $r$ is the distance from soil elements.

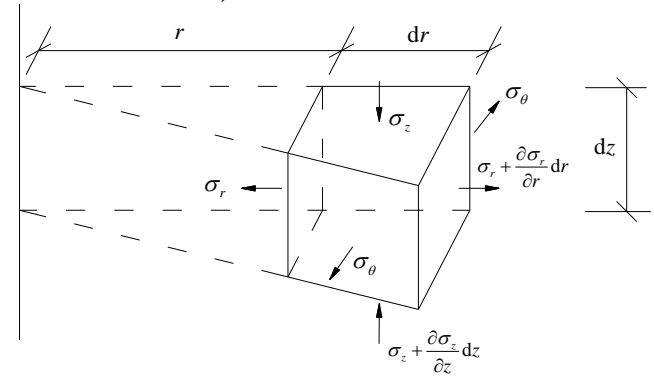

Fig. 2 Stress state of soil under axisymmetric condition

Under the axisymmetric condition of cavity expansion, the generalized shearing stress and generalized shearing strain exhibit the following relationship:

$$
\begin{aligned}
& q=\frac{1}{\sqrt{2}}\left[\left(\sigma_{r}-\sigma_{\theta}\right)^{2}+\left(\sigma_{z}-\sigma_{\theta}\right)^{2}+\left(\sigma_{r}-\sigma_{z}\right)^{2}\right]^{\frac{1}{2}} . \\
& \varepsilon_{s}=\frac{\sqrt{2}}{3}\left[\left(\varepsilon_{r}-\varepsilon_{\theta}\right)^{2}+\left(\varepsilon_{z}-\varepsilon_{\theta}\right)^{2}+\left(\varepsilon_{r}-\varepsilon_{z}\right)^{2}\right]^{\frac{1}{2}} .
\end{aligned}
$$

where $q$ is the generalized shearing stress, $\varepsilon_{s}$ is the generalized shearing strain, $\varepsilon_{z}$ is the vertical strain, $\varepsilon_{r}$ is the radial strain, $\varepsilon_{\theta}$ is the tangential strain.

Assuming the appropriate expression of the triaxial test, the generalized shearing stress and generalized shearing strain can also be expressed as: 


$$
q=\frac{\varepsilon_{s}}{D+\varepsilon_{s}} q_{u l t}
$$

where $D$ is the curve-fitting parameter and $q_{\text {ult }}$ is the ultimate shearing stress.

On the basis of conditions and assumptions, Ladanyi derived the single pile reaming from where radius is 0 in the clay foundation and considered the generalized shearing stress and strain as the function of $a / r$; the obtained generalized shearing strain can be expressed as

$$
\varepsilon_{s}=-\ln \left[1-\left(\frac{a}{r}\right)^{2}\right] .
$$

Substituting Formula (4) into Formula (3), the generalized shearing stress field of the soil around the pile after single pile reaming is determined as follows:

$$
q=-q_{u l t} \ln \left[1-\left(\frac{a}{r}\right)^{2}\right] / D-\ln \left[1-\left(\frac{a}{r}\right)^{2}\right] .
$$

Therefore, the generalized shearing stress and the generalized shearing strain of the soil around the pile in single pile reaming lay the theoretical foundation for the introduction of loess structural parameters.

\section{Introduction of loess structural parameters in single pile reaming}

To analyze the changing rule of loess structures under single pile reaming and in view of the single pile reaming study carried out in the $\mathrm{Q}_{3}$ loess layer of a pile testing engineering site in a loess plateau, this study obtains the relation curve of the generalized shearing stress $q$ and the generalized shearing strain $\varepsilon_{s}$ of an intact loess under different confining pressure conditions by conducting a conventional triaxial test (Fig. 3). Then, the fitting combination of the ultimate shearing stress $q$ ult and Formula (3) is realized to obtain a curve fitting parameter $D$ under different confining pressures.

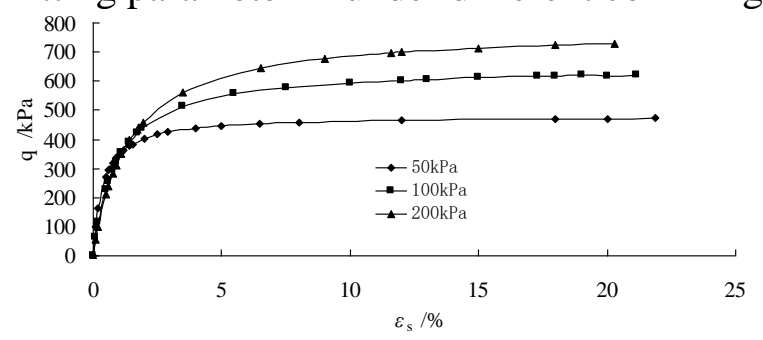

Fig. 3 Curve of generalized shear stress and strain of intact soil at a water content of $15 \%$

According to the results of the conventional triaxial test, qult values under 50, 100, and $200 \mathrm{kPa}$ should be 480,622, and $730 \mathrm{kPa}$, respectively. The corresponding fitting parameters $D$ under different confining pressures should be $0.3836,0.9225$, and 1.3425 . Under the condition of different confining pressures, the generalized shearing stress in Formula (3) can be expressed as follows: Under $50 \mathrm{kPa}$ confining pressure:

$$
q=480 \times \varepsilon_{s} /\left(0.3836+\varepsilon_{s}\right) .
$$

Under $100 \mathrm{kPa}$ confining pressure:

$$
q=622 \times \varepsilon_{s} /\left(0.9225+\varepsilon_{s}\right) .
$$


Under $200 \mathrm{kPa}$ confining pressure:

$$
q=730 \times \varepsilon_{s} /\left(1.3425+\varepsilon_{s}\right) .
$$

For the proposed structural parameter with stress ratio structural parameter $m_{\eta}$, it is divided into index and logarithmic forms [3]. However, taking the description method of these two structural parameters as objective laws to apply the finite element analysis increases the complexity of the computation. Therefore, $\mathrm{Li}$ et al. improved the description method of structural parameters [4] to generate the initial structural parameters in Formula (9) and the load disturbance structural parameters in Formula (10), in which $\mathrm{Q}_{3}$ loess test fitting parameter $H$ is 2.0.

$$
\begin{aligned}
& m_{\eta 0}=12.525-0.33467 w-0.01337 \sigma_{3} \\
& m_{\eta}=\left\{m_{\eta 0}+H \varepsilon_{s}\right\} /\left\{H \varepsilon_{s}+1.0\right\} .
\end{aligned}
$$

where $m_{\eta}$ is the load disturbance structural parameter, $m_{\eta 0}$ is the initial structural parameter, $w$ is the initial moisture content, $\sigma_{3}$ is the initial confining pressure, and $\varepsilon_{\mathrm{s}}$ is the generalized shearing strain.

To evaluate the pile foundation reaming effect on loess structural weakening, this study starts from the 0 radius for the generalized shearing strain of single pile reaming (substituting Formula (4) and Formula (9) into Formula (10) and then deriving the calculation formula of structural parameters of the loess around the pile after single pile reaming).

$$
m_{\eta}=\left\{12.525-0.33467 w-0.01337 \sigma_{3}-2 \times \ln \left[1-\left(\frac{a}{r}\right)^{2}\right]\right\} /\left\{-2 \times \ln \left[1-\left(\frac{a}{r}\right)^{2}\right]+1.0\right\}
$$

\section{Attenuation law of loess structural parameters in reaming}

In a test pile project on the Shaanxi Loess Plateau, the $\mathrm{Q}_{3}$ loess layer is approximately $23.0 \mathrm{~m}$ thick. The engineering test pile comprises precast pile and shows a test pile length of $15 \mathrm{~m}$ and a pile diameter of $500 \mathrm{~mm}$. The soil depth is approximately $3.5-4.5 \mathrm{~m}$. The indoor routine experimental determination indicates that the water content of the natural loess is $15 \%$, the natural density is 2.0 $\mathrm{g} / \mathrm{cm}^{3}$, and the dry density is $1.54 \mathrm{~g} / \mathrm{cm}^{3}$.

The embedded depths for analysis in this study are $2.5 \mathrm{~m}$ (point A), $5 \mathrm{~m}$ (point B), and $10 \mathrm{~m}$ (point C) in consideration of the loess shearing strength and the changing law of structural parameters (shown in Fig.4).

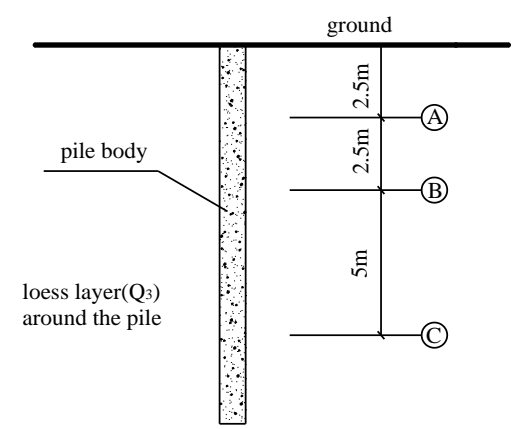

Fig. 4 Section of the single pile cavity expansion

The natural water content $w$ of structural loess is obtained with an indoor test. We substitute the initial stress $\sigma_{3}$ under different embedded depths into Formula (9) to determine the initial structural parameter value $m_{\eta 0}$. Under the embedded depths of $2.5,5$, and $10 \mathrm{~m}$, the initial structural parameters are $11.8063,11.1378$, and 9.8008 , respectively. The initial structural parameter distribution indicates that the initial structural parameter of the foundation top soil is the largest. From the foundation top, 
the initial structural parameters gradually decrease mainly because the foundation of the deep stress value is greater than the foundation stress value of the upper part.

In the embedded depth of $2.5 \mathrm{~m}, 5 \mathrm{~m}$ and $10 \mathrm{~m}$, the relationship between loess structural parameter $m_{\eta}$ and pile distance $r$ is shown in Fig. 5. The calculation analysis of single pile reaming shows that the structural parameter attenuation is severe within two times of the pile radius, minimal within two to four times of the pile radius, and almost absent for over four times of the pile radius.

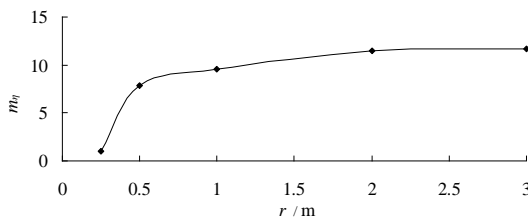

(a) depth of $2.5 \mathrm{~m}$

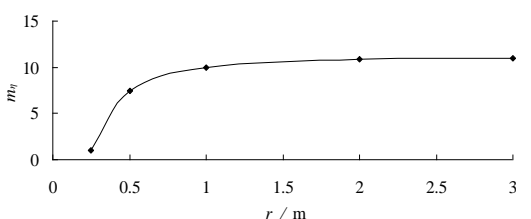

(b) depth of $5.0 \mathrm{~m}$

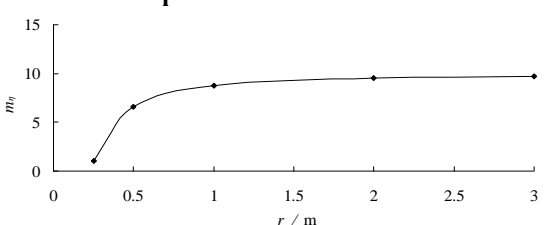

(c) depth of $10.0 \mathrm{~m}$

Fig. 5 Attenuation of structural parameter with the depth

\section{Conclusion}

On the basis of the theory of cavity expansion, this study analyzes the expression of the generalized shearing stress and generalized shearing strain of pile soil after reaming. It also introduces loess structural parameters to lay the foundation for the loess structural parameter analysis of pile soil after reaming.

The evaluation of the effect of single pile reaming on loess structural parameters indicates that with a decrease in the distance from the pile, the structural parameter of the foundation loess presents a nonlinear attenuation. With a minimal distance from the pile, the loess structural parameter attenuation is severe until the minimum value of 1.0 ; with an infinite distance from the pile, the loess structural parameter attenuation is close to the initial structural parameter of intact loess.

The calculation analysis of single pile reaming shows that the structural parameter attenuation is severe within two times of the pile radius, minimal within two to four times of the pile radius, and almost absent for over four times of the pile radius. Therefore, the obvious influence range for single pile reaming can be defined as two times of pile diameter.

\section{Acknowledgements}

This study was supported by the National Natural Science Foundation of China (11072193), Company limited of Changqing Science Technology (CTEC (2014) Z-KY-013).

\section{References}

[1] D.Y. Xie, J.L. Qi, Soil structure characteristics and new approach in research on its quantitative parameter, Chinese J. Geot. Eng. Vol.21(1999), p. 651-656.

[2] G.H. Deng, S.J. Shao, C.L. Chen, F.T. She, A structural parameter reflecting coupling action between shear stress and spherical stress, Rock and Soil Mechanics Vol.33 (2012), p. 2310-2314.

[3] R.J. Li, W. Zheng, J.D. Liu, R. Yan, S.J. Shao, Evaluation of stability of structural loess slope considering initial structural parameters, Rock and Soil Mechanics Vol.35 (2014), p. 143-150.

[4] H.S. Yu, Cavity Expansion Methods in Geomechanics, chapter, 5, Springer Netherlands (2000).

[5] B. Ladanyi, Expansion of a cavity in a saturated clay medium, Journal of the Soil Mechanics and Foundations Division, ASCE Vol.89 (1963), p. 127-161.

[6] I.F. Collins, H.S. Yu, Undrained expansions of cavities in critical state soils, International Journal for Numerical and Analytical Methods in Geomechanics Vol.20 (1996), p. 489-516. 